\title{
Taman Interaktif Di Waduk Pluit Sebagai Ruang Kegiatan Publik Bagi MASYaRAKat Di JaKaRTa
}

\author{
Tiara Maharani, Ana Hardiana, Ummul Mustaqimah \\ Program Studi Arsitektur \\ Jurusan Arsitektur Fakultas Teknik \\ Universitas Sebelas Maret Surakarta \\ Email: tiaramaharani31@gmail.com
}

\begin{abstract}
Designing Interactive Pluit Reservoir Park motivated by the needs unmet green space in the city of Jakarta. The existence of green space can be function as a public space by residents. Public space is a container that takes residents to interact socially in outer space. Pluit Reservoir is a new green space that also has another function as a public space. Green open space in the middle of the urban environment helps to improve the climate and environment of the city. Design issues is the need for Jakarta residents of an ideal public space can not be fully met by local governments such as the activities housed, circulation,utilities, as well as physical and psychological comfort. Design method used is based on the theory of an ideal open space concept. Ideal open space concept obtained through environmental comfort, convenience visitor psychology, the need of relaxation, active activities, and passive activities within the park. These criteria are the basis for the design of Interactive at Pluit Reservoir Park. The results obtained are design Interactive park that can accommodate not only residents but also social needs, make room for plants to grow and thrive for the preservation and welfare of the citizens of Jakarta.
\end{abstract}

Keywords: City Green Space, Interactive Park, Public space

\section{PENDAHULUAN}

Pada tahun 2013 Pemerintah Daerah Ibukota Jakarta melakukan upaya normalisasi fungsi Waduk Pluit. Salah satu upaya yang dilakukan oleh pemerintah adalah dengan mengembalikan fungsi bantaran waduk sebagai area peresapan atau ruang hijau. Ruang hijau pada bantaran waduk turut menambah luasan ruang hijau Kota Jakarta yang belum memenuhi standar jika dibandingkan dengan luas seluruh wilayah. Pemerintah DKI Jakarta kemudian membangun sebuah taman pada bantaran Waduk Pluit sebagai ruang publik bagi masyarakat Jakarta. Keberadaan taman ini mulai dimanfaatkan warga sekitar untuk bersosialisasi, dan melakukan kegiatan lainnya. Fasilitas yang disediakan di dalam taman tersebut belum seluruhnya dapat mengakomodasi kegiatan warga. Dalam perancangan Taman Interaktif yang dilakukan adalah mengutamakan fungsi taman sebagai area hijau perkotaan yang sekaligus berfungsi mengakomodasi kegiatan interaksi sosial antar warga sekitarnya. Taman Interaktif ini diharapkan dapat mewadahi seluruh kegiatan interaksi sosial masyarakat. Fasilitas yang disediakan mengandung unsur rekreasi dan edukasi yang dapat memancing warga untuk berinteraksi dalam area taman.

2. METODE

Metode perancangan merupakan langkah-langkah yang dilakukan dalam merancang Taman Interaktif di Waduk Pluit. Tahapan perancangan yang dilakukan adalah sebagai berikut:

1. Merumuskan permasalahan yang didapatkan setelah mengamati perilaku dan kegiatan pengunjung dalam taman. Permasalahan desain dalam Perancangan ruang terbuka antara lain kenyamanan 
pengunjung, kegiatan yang diwadahi, sirkulasi, serta utilitas dalam kawasan dengan tidak melupakan fungsi utama bantaran waduk yaitu sebagai ruang hijau.

2. Permasalahan desain diselesaikan dengan menganalisis data temuan di lapangan denganteori pendukung seperti ruang publik ideal, perancangan utilitas dalam kawasan, serta sirkulasi dalam kawasan.

3. Hasil akhir yang ingin dicapai adalah desain Taman Interaktif sebagai ruang publik bagi warga Jakarta yang memenuhi kebutuhan warga untuk berinteraksi sosial di ruang luar. Desain taman mengutamakan keberadaan area hijau dengan menambahkan fungsi ruang interaksi aktif warga kota. Kenyamanan pengunjung di ruang luar baik kenyamanan fisik dan psikologi. Taman Interaktif juga mewadahi kegiatan individu maupun kelompok yang dilakukan dalam taman.

\section{ANALISIS}

\subsection{Analisis Kegiatan}

Kegiatan yang direncanakan merupakan kegiatan yang dilakukan oleh pengunjung dari segala jenjang usia. Kegiatan yang direncanakan dilakukan baik oleh individu maupun kelompok.

1. Tujuan: menentukan kegiatan dalam taman berdasarkan teori Carmona (dalam Priyatmono, 2004) yaitu kriteria ruang publik ideal.

2. Dasar Pertimbangan: perumusan kegiatan berdasarkan kriteria active enggagement, passive enggagement, dan discovery (lihat Tabel 1).

Tabel 1. Kebutuhan Ruang

\begin{tabular}{|l|l|l|}
\hline $\begin{array}{l}\text { Kriteria ruang } \\
\text { Publik }\end{array}$ & $\begin{array}{l}\text { Jenis } \\
\text { Kegiatan }\end{array}$ & $\begin{array}{l}\text { Kebutuhan } \\
\text { Ruang }\end{array}$ \\
\hline $\begin{array}{l}\text { Active } \\
\text { Enggagement }\end{array}$ & $\begin{array}{l}\text { Membeli/ } \\
\text { menyewa } \\
\text { mainan }\end{array}$ & Kios mainan \\
\hline
\end{tabular}

\begin{tabular}{|l|l|l|}
\hline & $\begin{array}{l}\text { Membeli/ } \\
\text { menjual } \\
\text { makanan }\end{array}$ & $\begin{array}{l}\text { Kafetaria, } \\
\text { Kios jajanan }\end{array}$ \\
\hline Berolahraga & $\begin{array}{l}\text { Lapangan } \\
\text { basket, } \\
\text { futsal, dan } \\
\text { voli }\end{array}$ \\
\hline & Selancar air & Dermaga \\
\hline & $\begin{array}{l}\text { Membaca } \\
\text { dan } \\
\text { meminjam } \\
\text { buku }\end{array}$ & Perpustakaan \\
\hline Bermain air & $\begin{array}{l}\text { Kolam } \\
\text { renang dan } \\
\text { Plaza air }\end{array}$ \\
\hline $\begin{array}{l}\text { Passive } \\
\text { Enggagement }\end{array}$ & $\begin{array}{l}\text { Menanam } \\
\text { tanaman } \\
\text { suasana } \\
\text { taman }\end{array}$ & $\begin{array}{l}\text { Rumah } \\
\text { Hidroponik }\end{array}$ \\
\hline Discovery & $\begin{array}{l}\text { Mengebo, } \\
\text { Sidewalk } \\
\text { bantaran } \\
\text { waduk }\end{array}$ \\
\hline $\begin{array}{l}\text { menonton } \\
\text { pertunjukkan }\end{array}$ & $\begin{array}{l}\text { Mengadakan } \\
\text { bazaar }\end{array}$ & $\begin{array}{l}\text { Amphiteater } \\
\text { pameran } \\
\text { lapangan }\end{array}$ \\
\hline Aananan & Galeri \\
\hline
\end{tabular}

\subsection{Analisis Lokasi Tapak}

1. Tujuan: mendapatkan lokasi tapak pada bagian bantaran waduk. Pemilihan lokasi mempengaruhi fungsi ruang terbuka agar dipergunakan secara optimal untuk kegiatan publik.

2. Dasar Pertimbangan: Teori Whyte (dalam Priyatmono, 2004) mengenai kriteria lokasi ruang terbuka adalah sebagai berikut:

1. Lokasi tapak sesuai dengan tata guna lahan.

2. Memiliki lokasi yang strategis (sibuk) berdekatan dengan pemukiman dan pusat-pusat kegiatan warga.

3. Memiliki akses yang bagus secara visual dan fisik. Tapak mudah dikenali dan dijangkau dengan berjalan kaki maupun berkendara.

4. Tidak dilalui kendaraan padat dan kendaraan yang lewat memiliki kecepatan lambat.

\subsection{Analisis Pengolahan Tapak}

1. Tujuan: menentukan area terbangun dalam tapak 
2. Dasar Pertimbangan: PERMEN PU No. 5 tahun 2008 mengenai garis sempadan sungai dan waduk.

3. Proses Analisis: Taman kota memiliki kriteria $80 \%$ luas lahannya yang diperuntukkan sebagai lahan hijau. Dalam PERMEN PU No. 5 Tahun 2008 garis sempadan waduk berada pada 50 meter dari titik ketinggian normal air waduk. Area yang berada di dalam garis sempadan sungai tidak diperbolehkan untuk didirikan bangunan apapun (lihat Gambar 1)

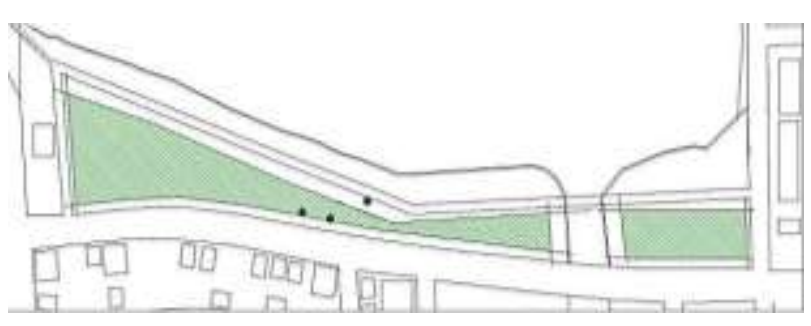

Gambar 1. Area Berwarna Hijau Merupakan Area Terbangun dalam Tapak

\subsection{Analisis Pencapaian}

Keberadaan jalur masuk taman tidak boleh membuat lalu lintas disekitarnya menjadi terhambat atau menimbulkan kemacetan.

1. Tujuan: menentukan letak pintu masuk dan area parkir yang sesuai dengan kondisi lalu lintas jalan.

2. Dasar Pertimbangan: Kemudahan akses oleh pejalan kaki maupun pengendara umum atau pribadi. Peletakkan entrance dan area parkir taman tidak menimbulkan kemacetan atau menghambat lalu lintas di sekitar tapak.

3. Proses Analisis:

Main Entrance pada taman disediakan beberapa untuk memberikan kesan terbuka sebagai ruang publik. Pintu masuk ke dalam area taman di buat pada tiap jarak 100-200 meter. Banyaknya pintu masuk ke dalam tapak dimaksudkan guna memudahkan pengunjung yang berjalan kaki untuk memasuki area taman (lihat Gambar 2).

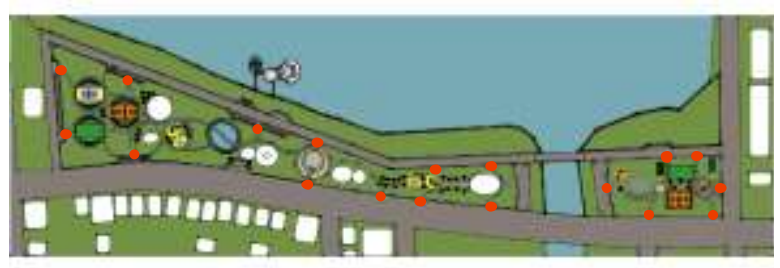

Gambar 2. Entrance Masuk ke Dalam Area Taman

Jalan retensi di tengah tapak diatur agar menjadi satu arah untuk mengontrol jumlah kendaraan yang melewati jalan tersebut. Tujuan perubahan arus tersebut untuk meminimalisir keramaian arus kendaraan pada jalan retensi.

Parkir kendaraan diletakkan pada area tapak yang berbatasan dengan jalan retensi. Titik-titik area parkir dibuat berdekatan dengan pusat-pusat kegiatan dalam taman. Peletakkan parkir pada jalan retensi bertujuan untuk menghindari penumpukkan kendaraan pada akses utama menuju tapak yaitu Jalan Pluit Timur Raya.

\subsection{Analisis Pemintakatan}

1. Tujuan: menentukan mintakat dalam tapak yang saling bersinergi dalam fungsinya sehingga memudahkan pengunjung dalam berkegiatan.

2. Dasar Pertimbangan: memberikan ruang bagi masing-masing fungsi agar dapat bekerja secara maksimal tanpa mengganggu satu sama lain namun tetap berdampingan secara harmonis

3. Proses Analisis: Taman Interaktif terbagi menjadi 4 zona fungsi kegiatan yaitu zona rekreasi (berwarna merah), zona edukasi (berwarna kuning), zona insidental (hijau) serta zona pengelola berwarna biru (lihat Gambar 3).

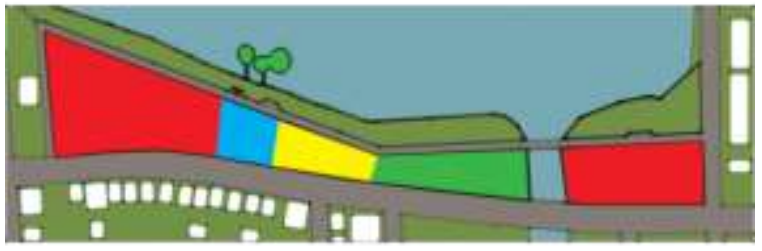

Gambar 3. Mintakat dalam Taman Interaktif Waduk Pluit. 
Zona pengelola diletakkan di tengah tapak untuk memudahkan pengawasan dalam taman. Zona kegiatan rekreasi ditetapkan pada area tapak yang berbatasan dengan pemukiman dengan maksud menarik perhatian warga untuk berkegiatan di dalam taman.

\subsection{Analisis Tampilan Bangunan}

1. Tujuan: desain bangunan yang mengutamakan fungsi lahan taman sebagai ruang hijau.

2. Dasar Pertimbangan: keberadaan bangunan sedapat mungkin tidak mempengaruhi keberadaan ruang hijau. Desain bangunan membaurkan ruang dalam dengan ruang luar yang alami.

3. Proses analisis: Keberadaan bangunan dalam area taman dapat mengurangi luasan area peresapan. Pada beberapa bangunan bertingkat dua, ruang bawah digunakan sebagai area peresapan sekaligus ruang interaksi sosial bagi warga. Material yang digunakan sebagai pembentuk ruang dalam bangunan adalah kaca tempered dan batu bata. Material kaca dipilih agar ruang luar yang hijau dan asri tetap dapat dirasakan oleh pengunjung walaupun berada di dalam ruang.

Secondary skin pada bangunan digunakan untuk mereduksi panas dari sinar matahari yang masuk ke dalam ruangan. Secondary skin yang digunakan berupa rangka baja ringan sebagai media tumbuh tanaman rambat. Green wall yang ditempatkan pada dinding masif bangunan dapat menambah estetika tampilan kawasan taman.

\subsection{Sirkulasi Kawasan}

1. Tujuan: menentukan konfigurasi jalur sirkulasi yang dinamis dan dapat menghubungkan setiap titik kegiatan.

2. Dasar pertimbangan: konfigurasi jalur yang dapat menyesuaikan dengan bentuk tapak yang memanjang dan terpisah oleh jalan retensi dan Kali Pakin.
3. Proses Analisis: Konfigurasi jalur linier merupakan sistem sirkulasi yang sesuai untuk digunakan di dalam taman. Konfigurasi jalur ini bersifat dinamis. Sirkulasi dibentuk dengan menetapkan satu sumbu yang menjadi penghubung antara satu area kegiatan dengan area kegiatan lainnya (lihat Gambar 4).

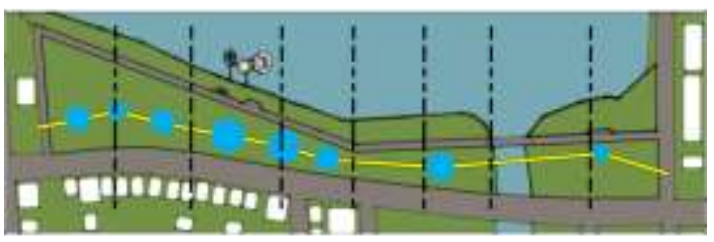

Gambar4. Konfigurasi Jalur Linier dalam Taman

Sirkulasi dalam taman memiliki lebar kurang lebih 2,5 meter dan dapat dilalui pejalan kaki dan pengendara sepeda secara bersamaan. Sirkulasi ini pula yang menjadi pengikat antar massa bangunan.

\subsection{Analisis Gubahan Massa}

1. Tujuan: menentukan gubahan massa yang menarik perhatian pengunjung sekaligus menjadi penanda kawasan Taman Interaktif Waduk Pluit.

2. Dasar Pertimbangan: bentuk massa bangunan yang responsif terhadap pergerakan aliran angin, sehingga tercipta bentuk yang sesuai dengan bentuk tapak, serta bentuk massa yang dinamis.

3. Proses Analisis: bentuk geometri seperti lingkaran, persegi dan segitiga menjadi dasar gubahan massa bangunan. Tapak berdekatan dengan daerah pesisir Laut Jawa, aliran angin yang berasal dari laut berpengaruh pada pemilihan gubahan massa. Bentuk lingkaran dapat menahan aliran angin sekaligus meneruskannya (lihat Gambar 5).
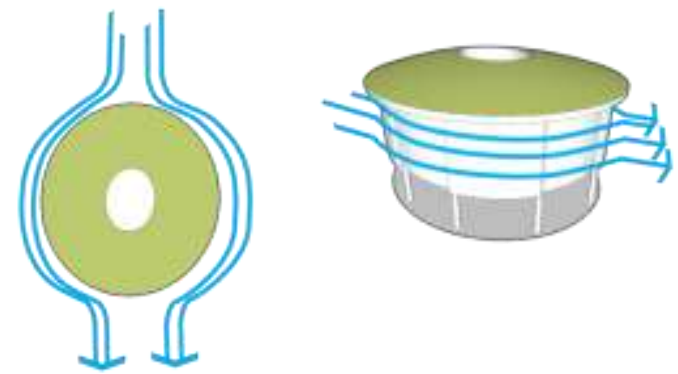

Gambar 5. Gubahan Massa Bangunan dari Bentuk Dasar Lingkaran 
Bentuk lingkaran yang kontras dengan massa bangunan di sekitarnya memudahkan pengunjung untuk mengenali area Taman Interaktif Waduk Pluit.

\subsection{Penataan Lanskap Kawasan}

1. Tujuan: menentukan elemen lanskap yang terdiri dari softscape, hardscape serta landmark yang dapat mendukung fungsi taman serta memberikan estetika.

2. Dasar Pertimbangan: elemen softscape (vegetasi) dan hardscape (perkerasan) yang digunakan dapat memaksimalkan penyerapan air ke dalam tanah dan menyerap zat polutan di udara.

3. Proses analisis: vegetasi dalam taman diperlukan untuk memperlambat aliran angin yang datang dari arah utara tapak.

Vegetasi yang digunakan antara lain pohon mahoni, pohon angsana, pohon trembesi, dan tanaman vetiver. Vegetasi tersebut memiliki fungsi antara lain sebagai peneduh, penyejuk, dan peresapan (lihat Gambar 6).

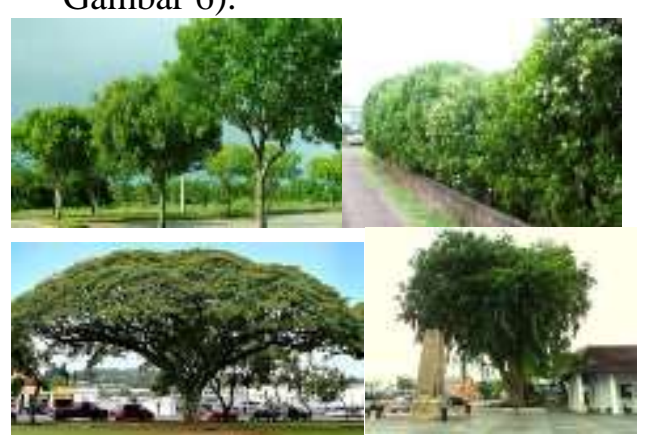

Gambar 6. Vegetasi dalam Area Taman Interaktif

Rumput gajah mini digunakan sebagai penutup permukaan tanah. Rumput dipilih untuk memberikan kenyamanan pengunjung yang ingin duduk santai mengobrol di lahan kosong dalam area taman

Tanaman kemuning dan soka merupakan vegetasi yang dimanfaatkan sebagai separator antara tapak Taman Interaktif dengan lingkungan sekitar.

Material grassblok pada jalur sirkulasi di dalam taman bertujuan untuk memaksimalkan peresapan air ke dalam tanah.

Pemberian landmark pada area plaza di dalam Taman Interaktif Waduk Pluit berupa air mancur, menjadi penanda sekaligus memberikan estetika dalam taman. Air mancur dalam taman memberikan kesejukan sekaligus efek relaksasi bagi pengunjung. Pengunjung taman dapat mengobrol santai pada tepian kolam sambil bermain air (lihat Gambar 7).

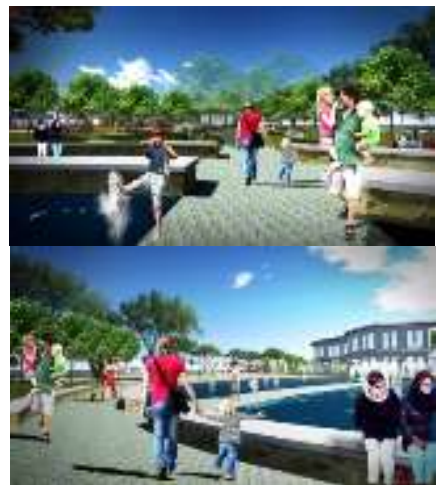

Gambar 7. Plaza Air yang Menjadi Landmark Taman

Sidewalk pada tepian waduk merupakan salah satu bagian taman yang menjadi landmark dalam taman. Adanya sidewalk dapat memfasilitasi kegiatan passive enggagement pengunjung dalam menikmati pemandangan waduk.

Tata cahaya artifisial memberikan nuansa yang berbeda antara Taman Interaktif Waduk Pluit dengan taman kota lainnya di Jakarta. Taman tetap terasa hidup pada malam hari dengan bantuan tata pencahayaan buatan yang memfasilitasi pengunjung untuk berkegiatan pada malam hari.

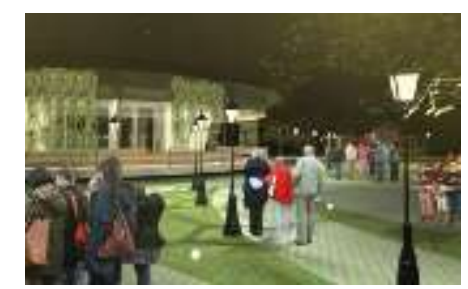

Gambar 8. Tata Cahaya di Malam Hari Mengidupkan Suasana Taman di Malam Hari.

\subsection{Utilitas Kawasan}

1. Tujuan: menentukan utilitas kawasan yang diperlukan untuk mendukung kelangsungan kegiatan dalam taman. 
2. Dasar Pertimbangan: Penyediaan listrik yang aman bagi pengunjung. Penggunaan CCTV untuk menjaga keamanan lingkungan taman. Fasilitas wi-fi diperlukan dalam area taman untuk memfasilitasi pengunjung dalam mendapatkan informasi. Lahan basah digunakan untuk mengolah limbah cair yang berasal dari dalam kawasan taman.

3. Proses analisis: Jaringan listrik disalurkan melalui jaringan bawah tanah yang kemudian masuk ke dalam bangunan. Pepohonan yang ada dalam tapak dapat mengganggu jaringan kabel listrik di udara. Kekurangan dari sistem jaringan listrik bawah tanah adalah bila terjadi kerusakan dalam jaringan sulit untuk segera diketahui.

Sistem keamanan menggunakan CCTV di beberapa tempat, terutama pada bagian tepian waduk, ruang duduk, dan fasilitas-fasilitas outdoor serta bangunan dalam kawasan taman. Penggunaan CCTV dapat membantu mengontrol keamanan serta kegiatan pengunjung yang dilakukan dalam taman. Fasilitas wi$f i$ dapat dimanfaatkan pengunjung pada area kafetaria, lapangan olahraga, bangunan pengelola, perpustakaan dan hall galeri.

Seluruh air kotor dalam kawasan Taman Waduk Pluit tidak langsung dibuang melalui saluran riol kota namun semua melewati proses pengolahan dalam lahan basah (wetland) terlebih dahulu sehingga aman untuk lingkungan. Pada lahan basah terdapat kolam pengendapan serta tanaman vetiver. Tanaman vetiver dapat menyerap zat polutan yang terlarut dalam air. Air hasil pengendapan dan penyerapan dalam lahan basah kemudian digunakan untuk kebutuhan penyiraman tanaman.

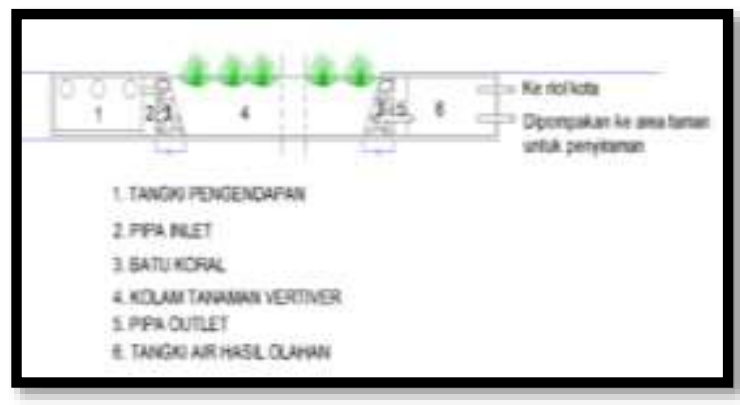

Gambar 9. Potongan Kolam Lahan Basah

\section{KESIMPULAN}

Dari hasil analisa serta hasil korelasi dari beberapa data di atas, maka diperoleh hasil berupa desain Taman Interaktif di Waduk Pluit sebagai berikut.

Nama : Taman Interaktif Waduk Pluit

Lokasi : Jalan Pluit Timur

$$
\text { Raya }
$$

Luas Lahan $\quad: \pm 71.028,5 \mathrm{~m}^{2}$

Luas Bangunan $: \pm 9.906,0 \mathrm{~m}^{2}$

Jumlah lantai : 2 lantai

Desain Taman Interaktif di Waduk Pluit mengusung fungsi ekologis sekaligus fungsi sosial. Konsep Taman Interaktif yang dihasilkan adalah penyediaan ruang untuk bertumbuh kembang bagi seluruh makhluk hidup tidak hanya manusia namun juga tumbuhan di areal perkotaan. Luas tapak taman sebesar $80 \%$ merupakan area hijau sedangkan $20 \%$ sisanya adalah area terbangun.

Kegiatan yang dirancang di dalamnya terdiri dari kegiatan interaksi sosial warga yang bersifat rekreatif dan edukatif.

Penerapan teori Carmona (dalam Priyatmono, 2004) yaitu kriteria ruang publik ideal diterapkan pada konsep kegiatan, serta desain taman yang berpengaruh pada kenyamanan pengunjung. Desain yang dihasilkan dalam Taman Interaktif Waduk Pluit antara lain:

1. Active Enggagement: yaitu kegiatan aktif pengunjung di dalam taman yaitu berolahraga, area bermain anak, area membaca, dan kolam air untuk bermain (lihat Gambar 10). 

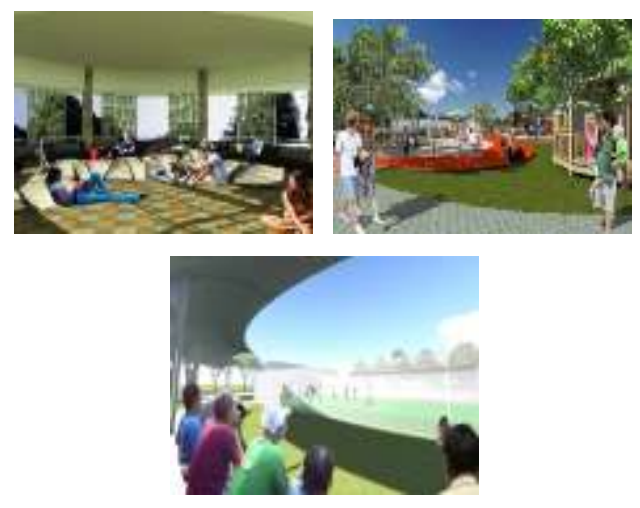

Gambar 10. Kegiatan Aktif yang Diwadahi dalam Taman.

2. Passive enggagement yaitu kegiatan pasif pengunjung di dalam taman seperti duduk santai, dan mengamati pemandangan waduk (lihat Gambar 11).

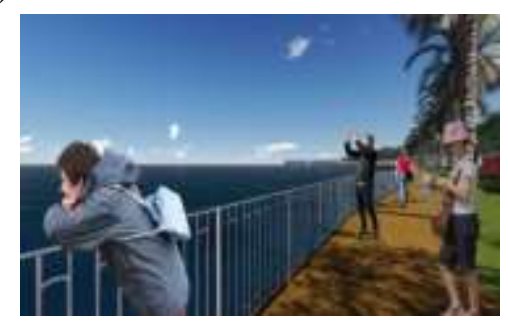

Gambar 11. Sidewalk di Tepian Waduk

3. Discovery yaitu kegiatan yang bersifat insidental yang dilakukan dalam taman. Kegiatan ini diwadahi dalam bangunan hall galeri, dan panggung terbuka di atas badan air waduk.

4. Pemanfaatan ruang bawah bangunan sebagai area peresapan serta ruang kegiatan sosial warga. Ruang bawah bangunan dimanfaatkan sebagai kios jajanan serta area wi-fi (lihat Gambar 12).

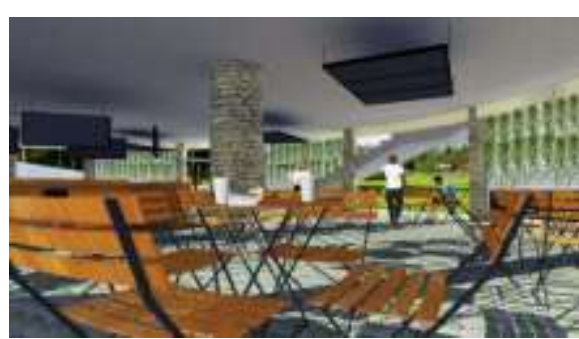

Gambar 12. Pemanfaatan Ruang Bawah

5. Elemen lanskap yang digunakan dalam taman tidak hanya menambah estetika namun juga berpengaruh terhadap kenyamanan fisik dan psikologi pengunjung.

6. Sirkulasi kawasan merupakan salah satu aspek penting dalam mengoptimalkan fungsi taman sebagai ruang sosial. Sirkulasi yang dinamis, mengarahkan pengunjung kepada kegiatan-kegiatan yang tersedia dalam area taman (lihat Lampiran 1).

\section{REFERENSI}

Priyatmono, Alpha Febela. (2004). Peran Ruang Publik Di Pemukiman Tradisional Kampung Laweyan Surakarta.

https://vetiverindonesia.wordpress.com/b uku-2/buku/4-fitoremediasi/ (diakses 28 november 2014) 


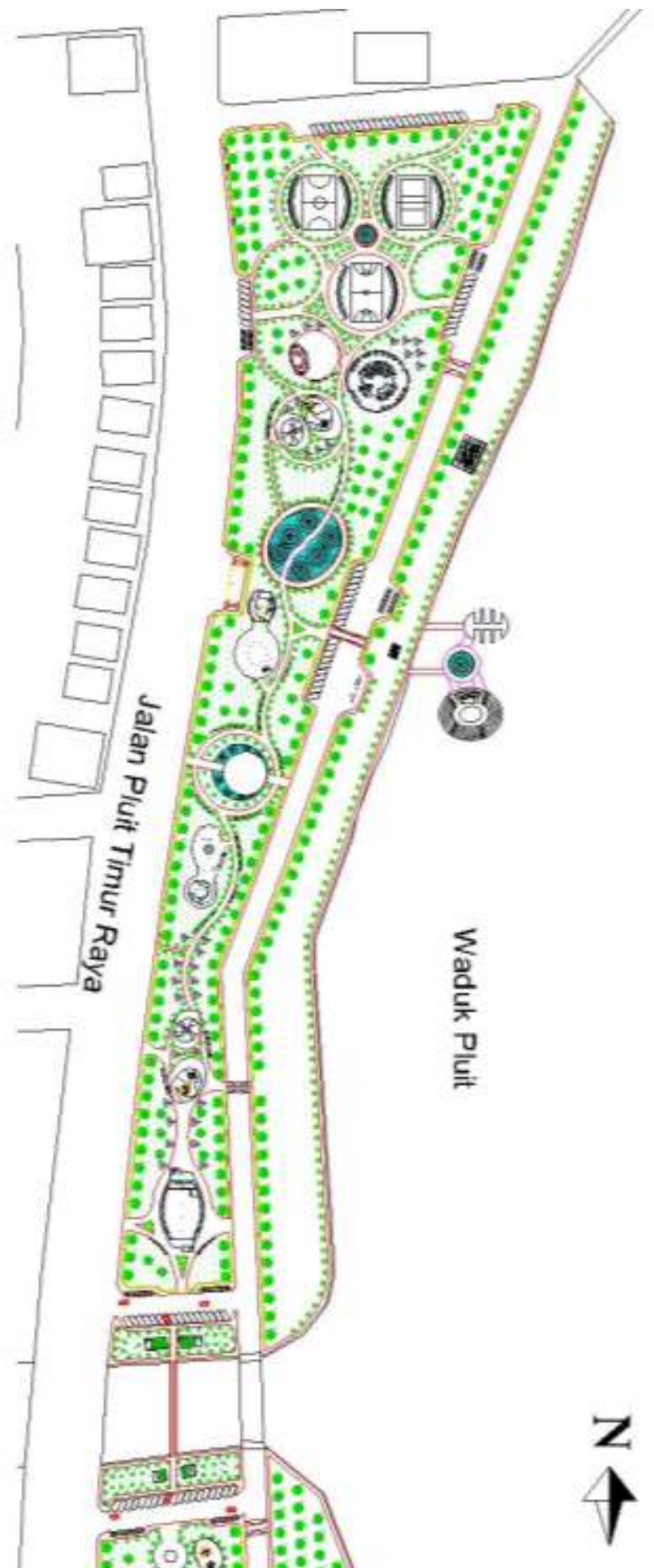


Lampiran 1. Rencana Tapak Taman Interaktif Waduk Pluit 